\title{
ISOLAMENTO E CULTIVO DE CÉLULAS TRONCO MESENQUIMAIS EXTRAÍDAS DO TECIDO ADIPOSO E DA MEDULA ÓSSEA DE CÃES
}

\section{ISOLATION AND CULTURE OF MESENCHYMAL STEM CELLS DERIVED FROM ADIPOSE TISSUE AND BONE MARROW OF DOGS}

\author{
Endrigo Gabellini Leonel Alves ${ }^{1^{*}}$ \\ Rogéria Serakides ${ }^{2}$ \\ Isabel Rodrigues Rosado ${ }^{1}$ \\ Jankerle Neves Boeloni ${ }^{3}$ \\ Natalia Melo Ocarino ${ }^{2}$ \\ Cleuza Maria de Faria Rezende ${ }^{2}$ \\ ${ }^{1}$ Universidade de Uberaba, Uberaba, MG, Brasil. \\ ${ }^{2}$ Universidade Federal de Minas Gerais, Belo Horizonte, MG, Brasil. \\ 3Universidade Federal do Espírito Santo, Alegre, ES, Brasil. \\ *Autor para correspondência - endrigoglalves@gmail.com
}

\section{Resumo}

Objetivou-se estabelecer um protocolo para extração, cultivo e expansão de células tronco mesenquimais (CTM), utilizando-se 3,0 mL da medula óssea e 3,0 $\mathrm{cm}^{3}$ de tecido adiposo do subcutâneo de três cães machos com seis meses de idade. As amostras foram processadas e as células extraídas e cultivadas em DMEM. Para comprovação do isolamento de CTM, procedeu-se a caracterização fenotípica e a diferenciação osteogênica, adipogênica e condrogênica. As células isoladas apresentaram morfologia alongada e fusiforme e capacidade de se diferenciar em osteoblastos, adipócitos e condrócitos. A caracterização fenotípica revelou alta expressão de marcadores de CTM CD90 (80,04\%) e CD29 (96\%) nas células de origem medular e CD90 (60,94\%) e CD29 (77,08\%) nas de origem adiposa. A expressão de marcadores hematopoiéticos foi baixa tanto nas células de origem medular CD45 (1,45\%) e CD34 (1,53\%), quanto nas de origem adiposa CD45 (1,45\%) e CD34 (1,53\%). As modificações e adaptações realizadas nos protocolos clássicos simplificaram o processo e foram eficientes, permitindo o isolamento e cultivo de CTM da medula óssea e do tecido adiposo de cães.

Palavras-chaves: cultivo celular; diferenciação; medicina regenerativa.

\footnotetext{
Abstract

The objective of this study was to establish a protocol for the isolation and culture of mesenchymal stem cells (MSC) from bone marrow and adipose tissue of dogs. Three 6-month-old male dogs were used. Approximately $3.0 \mathrm{~cm}^{3}$ of adipose tissue and $3.0 \mathrm{~mL}$ of bone marrow were collected. The 
samples were processed and the isolated cells were cultured in DMEM. The cells were subjected to phenotypic characterization and to osteogenic, adipogenic, and condrogenic differentiation to confirm the isolation of the MSC. The cells showed elongated and fusiform morphology and they were able to differentiate into osteoblasts, adipocytes, and chondrocytes. Phenotypic characterization revealed high expression of the MSC markers CD90(80.04\%) and CD29(96\%) in the cells from bone marrow and high expression of CD90(60.94\%) and CD29(77.08\%) in the cells from adipose tissue. In addition, phenotypic characterization revealed low expression of hematopoietic markers CD45(1.45\%) and CD34(1.53\%) in the cells from bone marrow and low expression of CD45(1.45\%) and CD34(1.53\%) in the cells from adipose tissue. Based on these results, the modifications applied to classical protocols simplified the process and proved to be efficient in the isolation, culture, and expansion of MSC isolated from the bone marrow and adipose tissue of dogs.

Keywords: cell culture; differentiation; regenerative medicine.

Recebido em: 19 fevereiro de 2015

Aceito em: 18 maio de 2017

\section{Introdução}

As pesquisas com células tronco (CT) representam um dos maiores desafios da ciência atual. As CT são capazes de se proliferar e de se diferenciar em vários tipos celulares dependendo das condições de cultivo ${ }^{(1,2)}$. Uma grande vantagem da terapia com CT recai sobre a utilização de células do próprio indivíduo sob tratamento sem risco de rejeição ${ }^{(3)}$.

As CT mesenquimais (CTM) são células multipotentes, encontradas entre as células diferenciadas de um tecido e com função de se auto-renovar e de se diferenciar, originando os tipos celulares do tecido no qual residem ${ }^{(1,4)}$. Algumas pesquisas têm sugerido que as CTM apresentam potencial de diferenciação próximo ao das CT embrionárias, podendo originar células de vários tecidos ${ }^{(2,5)}$, processo conhecido como plasticidade ${ }^{(1)}$. As CTM podem originar células do tecido ósseo ${ }^{(6)}$, tendíneo, cartilaginoso, adiposo e muscular e células não mesenquimais representadas pelas células neurais e epiteliais ${ }^{(7)}$. Vários tecidos são fontes de CT mesenquimais adultas, em maior ou menor número. Dentre eles tem-se: sistema nervoso central, pele, sangue periférico, fígado, trato gastrointestinal $^{(4)}$, sistema nervoso periférico, pâncreas, vasos sanguíneos, coração, córnea, retina ${ }^{(1)}$, músculo esquelético, membrana sinovial, periósteo ${ }^{(8)}$, pulmão, líquido amniótico ${ }^{(9)}$, sangue do cordão umbilical e placenta ${ }^{(3,9)}$. Contudo, a medula óssea ${ }^{(6,10)}$ e o tecido adiposo ${ }^{(6,11)}$ são considerados os principais sítios de CTM devido à maior quantidade e facilidade de obtenção dessas células.

As células tronco são hoje uma esperança para o tratamento de muitas doenças, mas seus protocolos de isolamento, cultivo e expansão são complexos e poucos detalhes metodológicos são apresentados nos estudos já publicados. Objetivou-se padronizar protocolos para extração, isolamento e expansão de células tronco mesenquimais de origem medular e adiposa em cães. 


\section{Material e Métodos}

Os procedimentos foram aprovados pelo Comitê de Ética em Experimentação Animal (CETEA) da UFMG (protocolo $\mathrm{n}^{\circ}$ 157/2009).

Utilizaram-se três cães, machos, intactos, sem raça definida, com seis meses de idade e massa corporal média de $15 \mathrm{~kg}$. Como medicação pré-anestésica, os animais receberam $1 \mathrm{mg} / \mathrm{kg}$ IM de xilazina (Calmiun, Agener União, Brasil) e $15 \mathrm{mg} / \mathrm{kg}$ IM de quetamina (Vetanarcol, Konig, Brasil), na mesma seringa. $\mathrm{O}$ membro pélvico direito foi submetido à tricotomia e preparado para cirurgia asséptica. A veia cefálica foi canulada e os animais receberam $3 \mathrm{mg} / \mathrm{kg}$ de propofol (Fresofol, Fresenius Kabi, Brasil) IV para intubação e manutenção anestésica. Como analgésico e antiinflamatório foi administrado 0,2 $\mathrm{mg} / \mathrm{kg}$ de meloxicam (Maxicam, Ouro Fino, Brasil) IM imediatamente após a indução anestésica.

A colheita da medula óssea foi realizada por punção aspirativa no platô tibial, pelo acesso medial, entre o ligamento patelar e o ligamento colateral medial, com agulha $16 \mathrm{G}$ com mandril, acoplada a uma seringa de $10 \mathrm{~mL}$ com 0,5 mL de heparina sódica (Parinex, Hipolabor, Brasil). Foi coletado 1,0 $\mathrm{mL}$ de medula óssea de cada animal, totalizando 3,0 $\mathrm{mL}$ de amostra final. As amostras de tecido adiposo foram coletadas cirurgicamente do subcutâneo da região glútea imediatamente acima do trocanter maior, sendo aproximadamente $1,0 \mathrm{~cm}^{3}$ de cada animal, totalizando cerca de $3,0 \mathrm{~cm}^{3}$.

Imediatamente após a coleta, as amostras de medula e de tecido adiposo foram colocadas separadamente em tubos falcon de $50 \mathrm{~mL}$ contendo $20 \mathrm{~mL}$ de meio de cultura Dulbecco's Modiffed Eagle Medium baixa glicose (DMEM, Gibco, USA), à temperatura ambiente, e encaminhadas para sala de cultura para realização dos protocolos de extração para cada tipo de tecido. As amostras de tecido adiposo e de medula óssea foram processadas separadamente para a obtenção de células tronco mesenquimais e caracterização fenotípica.

A amostra de medula óssea foi centrifugada por 10 minutos a 1400 rpm e levada para capela de fluxo laminar para manipulação asséptica. O sobrenadante foi desprezado e o pellet de células foi ressuspenso em $20 \mathrm{~mL}$ de meio de cultura para células tronco mesenquimais, DMEM com baixa glicose enriquecido com gentamicina $(60 \mu \mathrm{g} / \mathrm{L})$, penicilina $(100 \mathrm{U} / \mathrm{mL})$, estreptomicina $(100$ $\mu \mathrm{g} / \mathrm{mL}$ ), anfotericina ( $25 \mu \mathrm{g} / \mathrm{mL}$ ) [PAS, Sigma-Aldrich, USA] e 10\% de soro fetal bovino (Sorali, Brasil). Uma alíquota de 2,0 mL do meio com as células ressupensas foi transferida para cada garrafa de cultivo celular T75 (TPP, Switzerland, Germany) e 8,0 mL de meio adicionados em cada garrafa, sendo feitas cinco garrafas. Realizou-se homogeneização e incubação em estufa a $37{ }^{\circ} \mathrm{C}$ e $5 \%$ de $\mathrm{CO}_{2}$. Após 48 h, as células foram lavadas duas vezes com PBS 0,15 molar para remoção das hemácias e demais células não aderidas. O meio de cultivo foi trocado duas vezes por semana a fim de se eliminarem células hematopoéticas e adiposas não aderentes para obtenção somente de células tronco mesenquimais.

As amostras de tecido adiposo foram manipuladas em capela de fluxo laminar. Duas lavagens das amostras foram realizadas com PBS 0,15 molar. Para digestão do tecido conjuntivo e liberação das células, as amostras foram colocadas em outro tubo falcon de $50 \mathrm{~mL}$ contendo $20 \mathrm{~mL}$ de uma solução estéril de colagenase B (Roche, Germany) 0,1\% P/V. As amostras foram fragmentadas em aproximadamente de 1,0 a 2,0 mm de diâmetro com auxílio de uma tesoura cirúrgica. Em seguida, a 
amostra foi encubada em estufa a $37{ }^{\circ} \mathrm{C}$ e $5 \%$ de $\mathrm{CO}_{2}$ durante 45 minutos e a cada 15 minutos foi realizada vigorosa agitação para facilitar o processo de digestão. Transcorrido o tempo de digestão, procedeu-se a centrifugação por 10 minutos a $1400 \mathrm{rpm}$. O sobrenadante contendo a fração adiposa foi descartado e o pellet foi ressuspenso em $10 \mathrm{~mL}$ PBS 0,15 molar para lavagem e retirada dos resíduos de colagenase.

A amostra foi colocada em outro tubo falcon para reduzir a contaminação por gordura retida na parede do tubo e novamente centrifugada por 10 minutos a $1400 \mathrm{rpm}$. Após a centrifugação, o sobrenadante foi novamente descartado e o pellet, fração estromal, foi ressuspenso em $20 \mathrm{~mL}$ de meio de cultura para células tronco, o mesmo descrito para as células extraídas da medula. Uma alíquota de 2,0 mL do meio com as células ressupensas foi transferida para cada garrafa de cultivo celular T75 e 8,0 mL de meio foram adicionados em cada garrafa, sendo feitas cinco garrafas no total. Realizou-se homogeneização e incubação em estufa a $37{ }^{\circ} \mathrm{C}$ e $5 \%$ de $\mathrm{CO}_{2}$. Após 48 horas, foi realizada troca parcial do meio de cultura, renovando apenas 5,0 mL. Após mais 48 horas, as células foram lavadas duas vezes com PBS 0,15 molar para remoção de debris e células não aderidas. O meio de cultivo foi trocado duas vezes por semana a fim de se eliminarem células adiposas não aderentes garantindo a obtenção de células tronco mesenquimais.

Assim que foi atingido 80 a 90\% de confluência, realizou-se o repique das células. Para desprendimento das células, lavaram-se as garrafas com $10 \mathrm{~mL}$ de PBS 0,15 molar para retirada dos restos de meio de cultura, pois o soro fetal bovino pode inativar a tripsina. Após a lavagem, foi adicionado $1,5 \mathrm{~mL}$ de tripsina e a garrafa foi incubada por 10 minutos em estufa a $37^{\circ} \mathrm{C}$ e $5 \%$ de $\mathrm{CO}_{2}$. Transcorrido o tempo de ação da tripsina, a mesma foi inativada com 5,0 mL de DMEM enriquecido com $10 \%$ de soro fetal bovino. As garrafas foram então lavadas com o próprio meio para retirada das células e uma alíquota de 1,0 mL foi repicada para outra garrafa T75 com mais 9,0 $\mathrm{mL}$ de meio de cultura.

Após o terceiro repique, realizou-se a caracterização fenotípica das células quanto à expressão de CD90, CD29, CD45 e CD32. As células foram despendidas pela ação da tripsina e adicionou-se 1,0 mL de solução PBS $0,15 \mathrm{M}+10 \% \mathrm{SFB}+1 \%$ azida sódica à temperatura de $4{ }^{\circ} \mathrm{C}$ para fixação, evitando a internalização dos epitopos de interesse. As células foram quantificadas em câmara de Neubauer e semeadas na concentração de $1 \times 10^{5}$ células por poço em placas de 96 poços de fundo redondo. Foram feitos dois poços para controle negativo, dois poços para controle de marcação inespecífica só com anticorpo secundário (ab6730, abcam, Estados Unidos) e dois poços para cada marcador CD90 (ab22541, abcam, Estados Unidos), CD29-PE (ab64629, abcam, Estados Unidos), CD45 (ab22514, abcam, Estados Unidos) e CD32-PE (ab42902, abcam, Estados Unidos).

Após o plaqueamento, realizou-se centrifugação a 1400 rpm durante 10 minutos, o sobrenadante foi descartado e $100 \mu \mathrm{L}$ de anticorpo primário foram adicionados para cada marcador. A placa foi incubada protegida da luz a $4{ }^{\circ} \mathrm{C}$ por 30 minutos. Nos controles negativos e para marcação inespecífica adicionaram-se $100 \mu \mathrm{L}$ de PBS 0,15M + 3\% BSA. As diluições utilizadas para os anticorpos primários foram: 1/5 para o CD29-PE, 1/10 para o CD34-PE e 1/500 para o CD90 e CD45. A diluição dos anticorpos foi feita com solução de PBS 0,15 M + 3\% BSA. Transcorrido o período de incubação, procedeu-se a centrifugação das células por 10 min a $1400 \mathrm{rpm}$ e o sobrenadante foi descartado. As células foram lavadas três vezes com $200 \mu \mathrm{L}$ de PBS 0,15 M +3\% BSA a $4{ }^{\circ} \mathrm{C}$ para a retirada dos anticorpos não ligados. Em seguida, $100 \mu \mathrm{L}$ do anticorpo secundário 
foram adicionados nos poços referentes ao controle de ligação inespecífica e anticorpos primários não conjugados com fluoróforo CD90 e CD45. Os demais poços, controle negativo, CD29-PE e CD34-PE receberam $100 \mu \mathrm{l}$ de PBS 0,15 M +3\% BSA a $4{ }^{\circ} \mathrm{C}$. Incubaram-se as células por mais 30 minutos protegidas da luz a $4{ }^{\circ} \mathrm{C}$.

Após o período de incubação, realizou-se centrifugação por 10 min a 1400 rpm, o sobrenadante foi descartado e as células foram submetidas a três lavagens com $200 \mu \mathrm{L}$ de PBS 0,15 M + 3\% BSA a $4{ }^{\circ} \mathrm{C}$ para retirada dos anticorpos não ligados. Em seguida, ressuspenderam-se as células em $200 \mu \mathrm{L}$ de PBS $0,15 \mathrm{M}+10 \%$ SFB $+1 \%$ azida sódica a $4{ }^{\circ} \mathrm{C}$, por poço, e encaminhou-se para leitura no citômetro de fluxo FACScan (Fluorescence Activated Cell Analyser), empregando-se o software Cell Quest, com aquisição de 20000 eventos, tendo como parâmetros FSC e SSC em escala linear, FL1 (para FIFC) e FL2 (para PE) em escala logarítmica. Os dados foram analisados descritivamente pelo programa WinMDI por gráficos dot plot.

Para diferenciação adipogênica, as células de cada grupo foram submetidas, separadamente, à ação da tripsina e plaqueadas na densidade de $1 \times 10^{4}$ células $/ \mathrm{cm}^{2}$, em seis repetições em placas de seis poços. Após a obtenção de 60 a 70\% de confluência celular, o meio basal foi substituído por meio adipogênico, que é constituído de DMEM enriquecido com soro fetal bovino (10\%), dexametasona $(1 \mu \mathrm{M})$, insulina $(10 \mu \mathrm{L} / \mathrm{mL})$, indometacina $(100 \mathrm{mM})$ e isobutilmetilxantina $(500 \mathrm{mM})$. Em seguida, cultivaram-se as células a $37{ }^{\circ} \mathrm{C}$ e $5 \%$ de $\mathrm{CO}_{2}$ por 21 dias e o meio de cultura foi trocado a cada quatro dias. Transcorrido esse período, as células foram fixadas em formalina 10\% por 60 minutos, coradas pela técnica de Oil Red e avaliadas por microscopia óptica, para confirmação da diferenciação adipogênica.

Para diferenciação condrogênica, as células de cada grupo foram submetidas, separadamente, à ação da tripsina, $1 \times 10^{5}$ células de cada grupo foram semeadas em tubos falcon de $15 \mathrm{~mL}$ e cultivadas em meio basal por 24 horas. Após esse período, o meio basal foi substituído por meio condrogênico, que é constituído de DMEM enriquecido com soro fetal bovino (1\%), albumina sérica bovina $(0,0125 \mathrm{~g} / \mathrm{mL})$, piruvato $(100 \mu \mathrm{M})$, insulina $(6,25 \mu \mathrm{g} / \mathrm{mL})$, transferrina $(6,25 \mu \mathrm{g} / \mathrm{mL})$, ácido ascórbico $(50 \mu \mathrm{gM})$, dexametasona $(100 \mathrm{nM})$ e TGF- $\beta 1(10 \mathrm{ng} / \mathrm{mL})$. Em seguida, as células foram cultivadas a $37^{\circ} \mathrm{C}$ e $5 \%$ de $\mathrm{CO}_{2}$ por 21 dias e o meio de cultura foi trocado a cada quatro dias. Transcorrido esse período, os pellets celulares foram fixados em formalina $10 \%$ por 60 minutos e processados pela técnica rotineira de inclusão em parafina. Cortes histológicos com 5,0 $\mu \mathrm{m}$ de espessura foram corados pela técnica de PAS e avaliados por microscopia óptica, para confirmação da diferenciação condrogênica.

Para diferenciação osteogênica, as células de cada grupo foram submetidas, separadamente, à ação da tripsina e plaqueadas na densidade de $1 \times 10^{4}$ células $/ \mathrm{cm}^{2}$, em seis repetições em placas de seis poços (Techno Plastic Products in Trasadingen, Alemanha). Após a obtenção de 60 a $70 \%$ de confluência celular, o meio basal foi substituído por meio osteogênico, que é enriquecido com ácido ascórbico (50 $\mu \mathrm{g} / \mathrm{mL})$, ß-glicerofosfato (Sigma-Aldrich, USA) (10 mM) e dexametasona (Aché, Brasil) $(0,1 \mu \mathrm{M})$, acrescido de $10 \%$ de soro fetal bovino. Em seguida, as células foram cultivadas a $37^{\circ} \mathrm{C}$ e $5 \%$ de $\mathrm{CO}_{2}$ por 21 dias. Ao término desse período, as culturas foram fixadas em álcool $70 \%$ por 24 horas, coradas pelo método de Von Kossa adaptado de Alves et al. ${ }^{(6)}$ e avaliadas por microscopia óptica, para confirmação da diferenciação osteogênica. 


\section{Resultados}

A coleta da medula via platô tibial e de tecido adiposo na região subcutânea glútea mostrou-se de fácil execução e sem complicações pós-operatórias. Os 3,0 mL de medula óssea e cerca de 3,0 $\mathrm{cm}^{3}$ de adiposo foram suficientes para se realizar o isolamento das células tronco mesenquimais, obtendo-se células aderidas à superfície da garrafa de cultivo às 24 e 72 horas de incubação, respectivamente. A heparina na concentração utilizada impediu a coagulação da amostra de medula. O protocolo utilizado para digestão do tecido adiposo permitiu o isolamento das células tronco mesenquimais do tecido adiposo (CTM-AD). Os protocolos utilizados para isolamento e expansão das células tronco mesenquimais da medula óssea (CTM-MO) e CTM-AD foram eficientes e possibilitaram a manutenção de ambas as culturas até a décima passagem, quando foram descartadas. Tanto as CTM-MO quanto as CTM-AD apresentaram morfologia alongada, fusiforme, semelhante à morfologia de fibroblastos (Fig. 1).

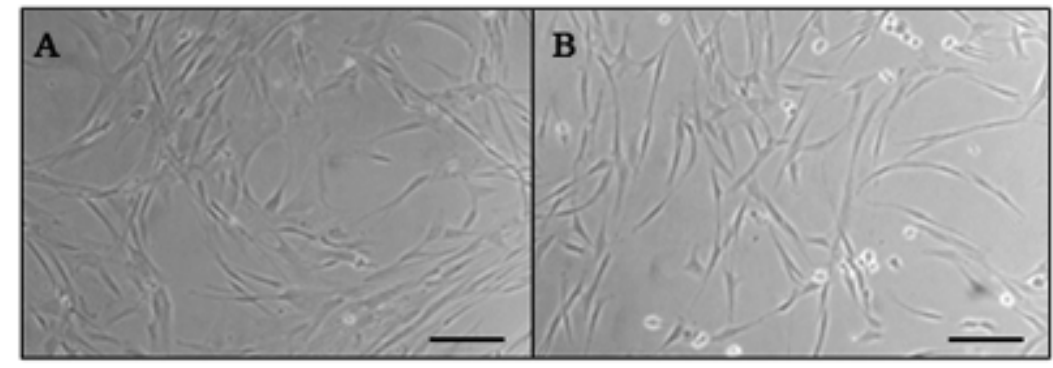

Figura 1. Fotomicroscopia de contraste de fases das células tronco mesenquimais extraídas de medula óssea (A) e do tecido adiposo de cães (B). Observar a morfologia alongada, fusiforme das células. A barra corresponde a $70 \mu \mathrm{m}$

Durante a fase de isolamento, a adesão das CTM-MO foi observada às 48 horas e das CTM-AD às 72 horas. No entanto, após a aderência, as CTM-AD apresentaram uma multiplicação mais rápida atingindo $80 \%$ de confluência aos sete dias de cultivo, enquanto as CTM-MO atingiram a mesma confluência aos 15 dias. As passagens foram realizadas em média a cada sete dias para as CTM-AD e 10 dias para as CTM-MO.

Após o terceiro repique e caracterização fenotípica por citometria de fluxo, as CTM-MO apresentaram baixa expressão de marcadores de células hematopoiéticas CD45 (1,45\%) e CD34 (1,53\%) e alta expressão de marcadores de células tronco CD90 (80,04\%) e CD29 (96\%) (Fig. 2).

Decorrido o terceiro repique e a caracterização fenotípica por citometria de fluxo, as CTM-AD de cães apresentaram baixa expressão de marcadores de células hematopoiéticas CD45 (1,54\%) e CD34 (0,88\%) e alta expressão de marcadores de células tronco CD90 (60,94\%) e CD29 (77,08\%), (Fig. 3). Ambas as culturas apresentaram um crescimento mais lento a partir da oitava passagem.

As CTM-AD e CTM-MO mostraram a formação de nódulos de mineralização após 21 dias de 
cultivo em meio osteogênico, caracterizando sucesso na diferenciação osteogênica (Fig. 4). Verificou-se o acúmulo de vesículas lipídicas com aspecto birrefringente e coloração avermelhada por Sudan no interior do citoplasma das CTM-MO e CTM-AD após 21 dias de cultivo em meio adipogênico, o que caracteriza a diferenciação adipogênica dessas células (Fig. 4). Após 21 dias de cultivo em meio condrogênico, foi possível observar a diferenciação das CTM-MO e CTM-AD em condrócitos com o acúmulo de proteoglicanos corados em violeta vivo no interior do citoplasma e na matriz extracelular (Fig. 4).

Selected Population MSC-BM

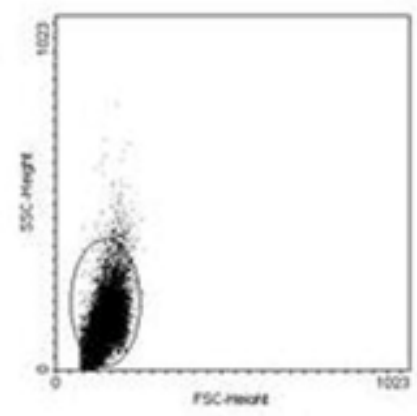

CD $45-1,49 \%$

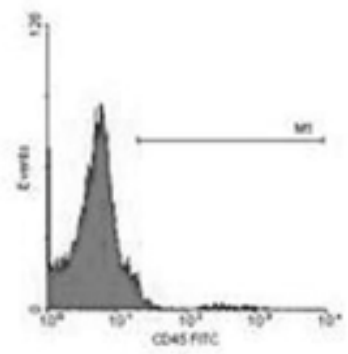

BlankFL1 - 0,41\%

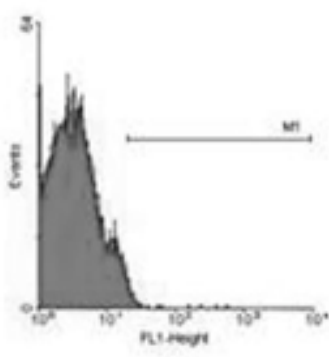

FITC $-0,67 \%$

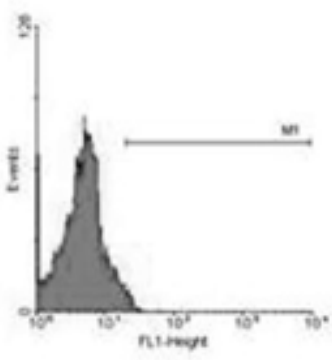

CD $90-80,04 \%$

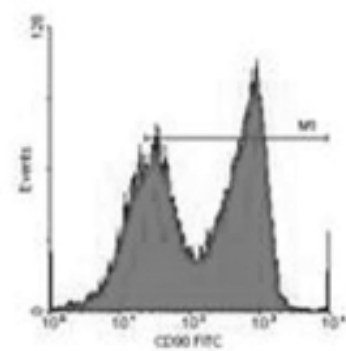

Blank FL2 - 0,4\%

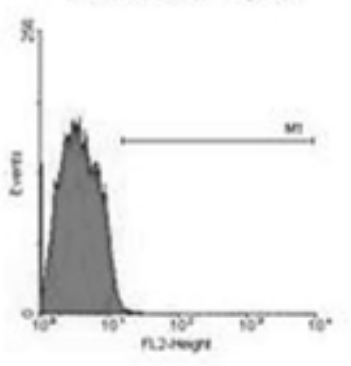

CD29- $96 \%$

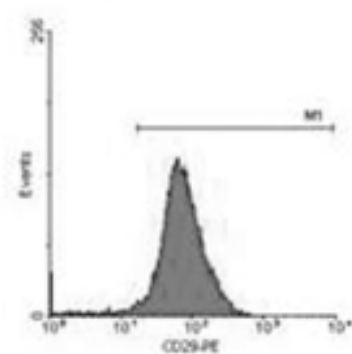

CD $34-1,53 \%$

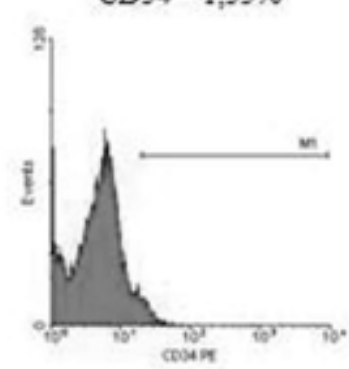

Figura 2. Histogramas da expressão de CD45, CD34, CD90 e CD29 por citometria de fluxo em células tronco mesenquimais da medula óssea de cães cultivadas em DMEM após o terceiro repique e confluência de 80 a $90 \%$. Os histogramas mostram a escala de fluorescência no eixo $\mathrm{x}$ considerada positiva quando o pico de células está acima de $10^{1}$ ou seja, toda a área do gráfico que se encontra no intervalo da barra M1 é positiva. 
Selected Population MSC-AD

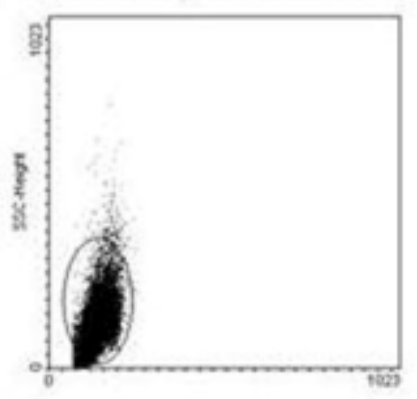

$\mathrm{CD} 45 \cdot 1,54 \%$

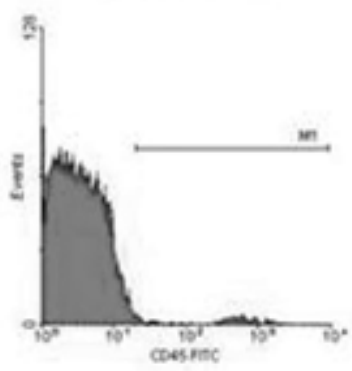

Blank FL 1 - $0,14 \%$

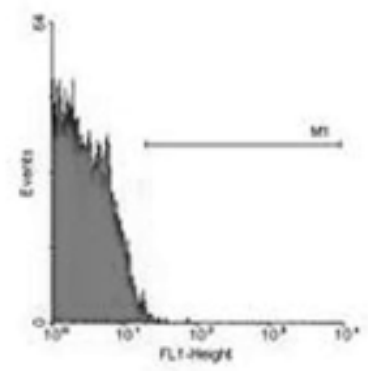

FITC $\cdot 0,49 \%$

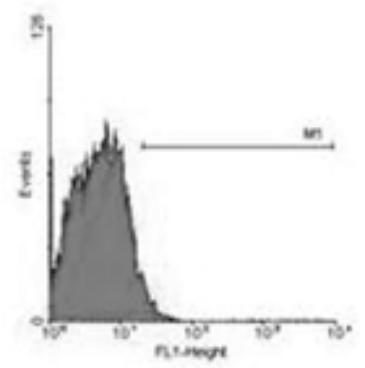

$\mathrm{CD} 90-60,94 \%$

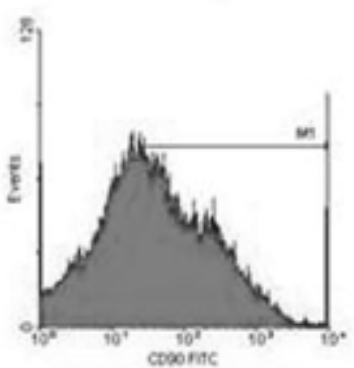

Blank FL2 - $0,34 \%$

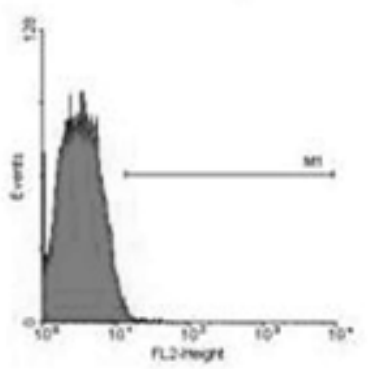

CD29- $77,08 \%$

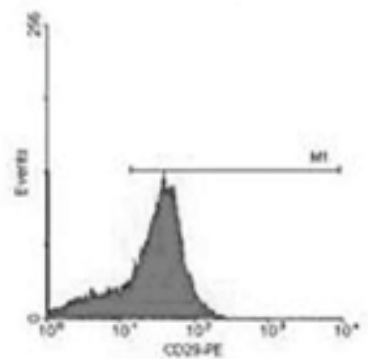

$\mathrm{CD} 34 \cdot 0,88 \%$

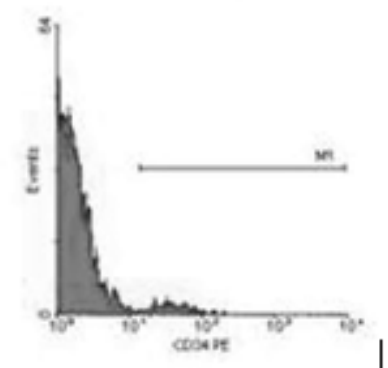

Figura 3. Histogramas da expressão de CD45, CD34, CD90 e CD29 por citometria de fluxo em células tronco mesenquimais do tecido adiposo de cães cultivadas em DMEM após o terceiro repique e confluência de 80 a $90 \%$. Os histogramas mostram a escala de fluorescência no eixo $\mathrm{x}$ considerada positiva quando o pico de células está acima de $10^{1}$ ou seja, toda a área do gráfico que se encontra no intervalo da barra M1 é positiva. 


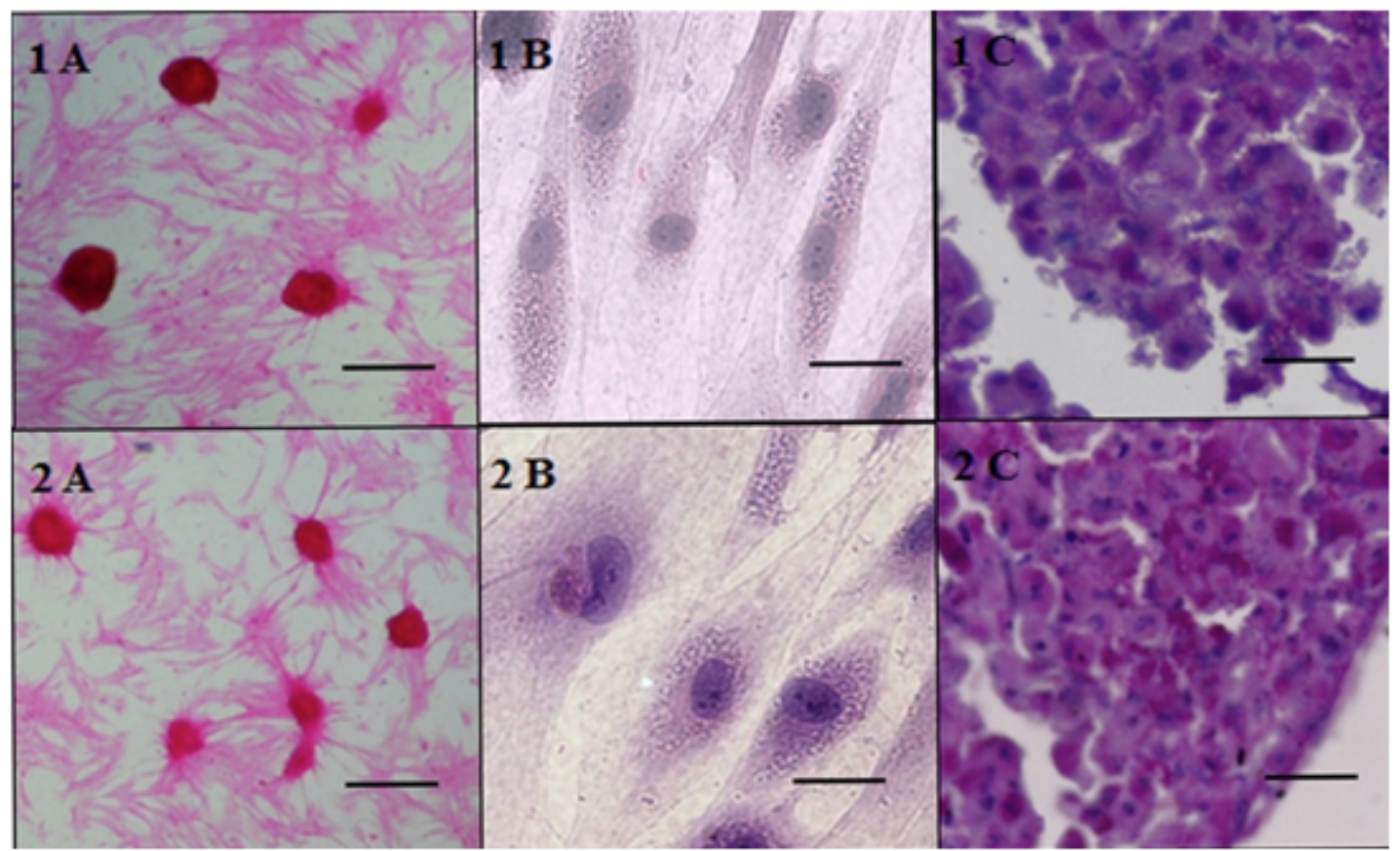

Figura 4. Cultura de células tronco mesenquimais extraídas da medula (1) e do tecido adiposo (2) de cães submetida à diferenciação osteogênica (A), adipogennica (B) e condrogênica (C) por 21 dias. Observar nas imagens $1 \mathrm{~A}$ e $2 \mathrm{~A}$ os nódulos de mineralização corados em vermelho pela técnica de Von Kossa; nas imagens $1 \mathrm{~B}$ e $2 \mathrm{~B}$ as vesículas lipídicas com aspecto birrefringente e coloração avermelhada no interior das células coradas pela técnica Oil Red e nas imagens $1 \mathrm{C}$ e $2 \mathrm{C}$ os proteoglicanos corados em violeta vivo pela técnica de PAS. Barras das imagens $1 \mathrm{~A}$ e $2 \mathrm{~A}=350 \mu \mathrm{m}$ e das imagens $1 \mathrm{~B}, 2 \mathrm{~B}, 1 \mathrm{C}$ e $2 \mathrm{C}=8,75 \mu \mathrm{m}$.

\section{Discussão}

A ausência de morbidade e de complicações no local de coleta da medula, observado no presente estudo, confirma que a punção no platô tibial é uma alternativa viável e de fácil execução para a coleta de medula óssea em cães. No entanto, outros locais como tubérculo maior do úmero ${ }^{(12)}$, fossa trocantérica do fêmur ${ }^{(13)}$ e crista ilíaca ${ }^{(14)}$ podem também ser utilizados com sucesso para coleta de medula. Nos casos em que o paciente apresenta uma enfermidade cirúrgica, comumente faz-se a coleta da amostra de medula óssea no local mais próximo da intervenção ${ }^{(13,10)}$. Assim como realizado neste estudo, o emprego de uma agulha de 16 ou $18 \mathrm{G}$ com mandril evitou sua obstrução e a necessidade de uma nova punção. A não observação de complicações no local de colheita das amostras de medula óssea condiz com a maioria dos relatos dessa prática em cães ${ }^{(15)}$, diferente da realizada no ser humano, que tem sido associada a dor pós-operatória e inflamação no local de coleta $^{(16)}$.

A heparina, anticoagulante empregada neste trabalho é também a mais utilizada em pesquisas semelhantes $^{(14,17)}$. Entretanto, outros anticoagulantes, como o EDTA na proporção de 1:1 com a medula, podem ser utilizados ${ }^{(18)}$. Em situações nas quais não se pode utilizar anticoagulante devido à natureza do estudo, a medula pode ser colhida em meio de cultura na proporção de $1: 1^{(10)}$. A utilização de anticoagulante é necessária para se evitar a formação de coágulos que podem aprisionar as CTM e impedir sua aderência à superfície plástica da garrafa de cultivo. 
Pode-se afirmar que o método aqui empregado é vantajoso por reduzir a quantidade de amostra necessária para o isolamento de CTM-MO, com mínima manipulação das células por eliminar etapas no seu processamento, o que diminui o risco de perda de viabilidade e morte celular. Isto é vantajoso especialmente em animais de pequeno porte e Toy, que possuem ossos pequenos que dificultam ou impossibilitam a colheita de grandes quantidades de medula óssea. As técnicas tradicionais requerem maior quantidade de medula $(10 \text { a } 25 \mathrm{~mL})^{(10,12,17)}$ e maior manipulação das células durante o processo de isolamento, o que pode interferir na sua viabilidade.

A aderência de grande quantidade (aproximadamente $40 \%$ de confluência) de CTM-MO à superfície da garrafa, observada às 48 horas de cultivo, mostrou eficiência no isolamento das CTMMO a partir da medula óssea sem a separação das células mononucleares. O número de células isoladas por grama de medula óssea é variável de acordo com a espécie, com a idade do paciente e com o tipo de processamento da amostra. Alguns pesquisadores utilizam a hemólise para separação das células mononucleares e isolamento das $\mathrm{CTM}-\mathrm{MO}^{(12)}$, outros usam técnicas de separação por gradiente de concentração ${ }^{(13,19)}$, mas, no presente estudo, observou-se que não é necessária a separação da fracção mononuclear para se isolar as CTM de amostras de medula óssea de cães.

Em um estudo com CTM-MO de ratos, Yoshimura e colaboradores $^{(8)}$ isolaram um número significativamente maior de CTM-MO a partir de amostras de medula sem prévia separação da fração mononuclear. Spencer e colaboradores ${ }^{(10)}$ relataram um alto rendimento no isolamento de células mononucleares de amostra de medula de cão $\left(1.6 \times 10^{7}\right.$ células por $\mathrm{mL}$ de medula óssea) a partir da técnica de centrifugação com gradiente de concentração em FICOLL ${ }^{\circledR}$. Chung e colaboradores $^{(14)}$ obtiveram um rendimento menor $\left(1,2 \times 10^{5}\right.$ células por $1,0 \mathrm{~mL}$ de medula óssea) utilizando Hank's Balanced Salt Soluction ${ }^{\circledR}$ para centrifugação da amostra. Entretanto, os resultados acima apresentados não podem ser interpretados como rendimento de CTM por grama de tecido, visto que nem todas as células mononucleares presentes na medula são células tronco mesenquimais. Um grande número delas é representado por leucócitos e células tronco hematopoiéticas ${ }^{(8)}$.

A incubação da medula é necessária durante a aderência das CTM à superfície da garrafa de cultivo celular por permitir o seu isolamento. Diferentes tempos de incubação são recomendados como $48^{(14)}$, 72 horas $^{(12,18)}$, quatro dias ${ }^{(13)}$ e sete dias ${ }^{(17)}$. O presente trabalho mostrou que a incubação por 48 horas é suficiente para a aderência das CTM-MO caninas. Após o isolamento, as CTM se multiplicam e requerem um tempo para atingir a confluência de $80 \%$, considerada mínima para realização da primeira passagem ${ }^{(5)}$. Neste estudo, o período de 15 dias, superior a 8-10 dias relatados por Spencer e colaboradores ${ }^{(10)}$, não impediu a expansão da CTM-MO e pode ter ocorrido devido à diferença de técnica empregada.

O tecido adiposo pode ser colhido de vários locais com subcutânea ${ }^{(14,20,22)}$, inguinal(5), viseral ${ }^{(21)}$, infrapatelar $^{(10)}$ e omento ${ }^{(5)}$, mas o obtido do subcutâneo da região glútea, local utilizado nesta pesquisa, apresentou melhor rendimento $\left(5,28 \times 10^{5} \text { células por grama de tecido }\right)^{(5)}$. Esse local foi de fácil acesso e permitiu a colheita do tecido adiposo com menor presença de vasos sanguíneos e tecido conjuntivo, o que facilitou a digestão e propiciou menor contaminação da cultura por outros tipos celulares como fibroblastos e células endoteliais.

A colheita do tecido adiposo pode ser feita por biópsia aberta ${ }^{(14)}$, como a realizada neste trabalho. É preferível em cães por proporcionar uma amostra de tecido adiposo com menor quantidade de vasos, tecido conjuntivo e sangue. Os $3,0 \mathrm{~cm}^{3}$ de tecido adiposo utilizados nessa pesquisa foram suficientes para extração de CTM-AD, quantidade inferior à utilizada em outros estudos, como 5,0 
$\mathrm{g}^{(22)}$ e 7,0 $\mathrm{g}^{(21)}$. Segundo Vieira e colaboradores ${ }^{(20)}, 100 \mu \mathrm{m}$ de tecido adiposo é o volume mínimo para se isolar CTM-AD caninas.

O protocolo de isolamento de células tronco mesenquimais do tecido adiposo aqui utilizado mostrou-se eficiente e simples por não ter utilizado a filtração durante o processo de isolamento das CTM-AD. O isolamento celular passa por uma fase inicial de digestão da matriz extracelular ${ }^{(11)}$. É uma etapa crítica e deve ser controlada de forma que a matriz extracelular seja degradada, mas que não haja lesão e perda de viabilidade celular. Portanto, é necessário padronizar o tipo de enzima e a concentração utilizada, a quantidade e o tamanho dos fragmentos teciduais e os períodos de incubação durante o processo ${ }^{(5,10,14,21,22)}$.

Existem várias colagenases que podem ser utilizadas como as dos tipo $\mathrm{I}^{(10,14,21)}$, tipo $\mathrm{IA}^{(5)}$ e tipo II $^{(22)}$. Nesta pesquisa, a colagenase B foi efetiva na digestão do tecido adiposo e permitiu a degradação da matriz extracelular e a liberação das células sem o comprometimento de sua viabilidade.

A eliminação da fase de filtração foi efetuada considerando que a menor manipulação das células é favorável à sua viabilidade, como aqui observado. Nos protocolos clássicos para extração de CTM$\mathrm{AD}$, há uma fase de filtração após a digestão tecidual cujo objetivo é retirar os debris oriundos da degradação da matriz extracelular ${ }^{(14,20-22)}$. O tempo de 72 horas de incubação para a aderência da CTM-AD à superfície da garrafa foi maior do que o relatado por outros pesquisadores, 12 horas ${ }^{(21)} \mathrm{e}$ 48 horas $^{(14,20)}$. Entretanto, não houve prejuízo para o isolamento das CTM-AD que atingiram confluência de $80 \%$ em sete dias de cultivo, o mesmo tempo relatado por Spencer e colaboradores $^{(10)}$, que utilizaram a etapa de filtração, ratificando que a filtragem é desnecessária e sua ausência não atrapalha o isolamento e expansão das CTM-AD.

A eficiência do DMEM como meio de cultivo de CTM aqui observada é também referida pela maioria dos estudos com CTM caninas $^{(9,10,13,17,18,20-23)}$; no entanto, outros meios como RPMI ${ }^{(14)}, \alpha-$ $\operatorname{MEM}^{(19,22)}, \mathrm{MEM}^{(5)}$ e $\mathrm{IMDM}^{(12)}$ já foram utilizados com sucesso para o isolamento, cultivo e expansão de CTM caninas. A suplementação do meio de cultura com $10 \%$ de soro fetal bovino (SFB) assim como relatado em outros estudos ${ }^{(5,9,12-14,17,18,20-23)}$ foi suficiente para permitir a expansão e diferenciação das CTM. Apenas em uma pesquisa com CTM caninas utilizou-se quantidade maior de SFB 20\%(10). A suplementação do meio de cultura com soro fetal bovino foi indispensável para o cultivo, expansão e diferenciação de CTM. Sua ausência pode levar à redução da proliferação celular ${ }^{(22)}$ e ao aumento da apoptose ${ }^{(21)}$. O crescimento mais lento de ambas as culturas CTM-MO e CTM-AD após a oitava passagem foi também observado por Martinello e colaboradores $^{(21)}$, que atribuíram à senescência das culturas que apresentaram significativa redução na concentração da telomerase após a oitava passagem.

A forma alongada semelhante a fibroblasto das CTM-MO e CTM-AD aqui observada mostrou-se eficiente no isolamento das CTM, sendo a morfologia das CTM definida como padrão pela The International Society for Cellular Therapy ${ }^{(2)}$ e relatada por outros pesquisadores ${ }^{(10,14,21)}$. A alta expressão de marcadores de células tronco, baixa de marcadores de células hematopoiéticas e capacidade de diferenciação em osteoblastos, adipócitos e condrócitos observadas nas CTM confirmaram a eficiência no isolamento das CTM a partir de amostras de medula óssea e de tecido adiposo, padrão mundialmente aceito como característico de células tronco mesenquimais ${ }^{(2,10,12,18-}$ 21).

The International Society for Cellular Therapy definiu que as CTM devem expressar marcadores como CD105, CD73 e CD90 e não expressar marcadores de células hematopoiéticas, além de serem capazes de se diferenciar em osteoblastos, adipócitos e condrócitos ${ }^{(2)}$. No presente estudo, tanto as 
CTM-MO quanto as CTM-AD mostraram uma alta expressão de CD90, marcador característico de células tronco mesenquimais ${ }^{(12,20,21)}$ e baixa expressão de CD45 e CD34, marcadores de células hematopoiéticas $^{(2)}$, excluindo a possibilidade de isolamento de células tronco hematopoiética especialmente na cultura extraída da medula óssea. Além disso, as culturas de CTM isoladas neste experimento apresentaram alta expressão de CD29, outro marcador de células tronco ${ }^{(18,20)}$ que não é expresso por fibroblastos caninos $^{(12)}$, excluindo a possibilidade do isolamento de fibroblastos principalmente na cultura extraída do tecido adiposo.

\section{Conclusão}

As modificações e adaptações realizadas nos protocolos de extração, isolamento e expansão de células tronco da medula óssea e do tecido adiposo de cães foram eficientes e simplificaram o processamento.

\section{Agradecimentos}

Os autores agradecem à FAPEMIG pelo financiamento do projeto de pesquisa, ao CNPq pela bolsa de estudo de doutorado, à Escola de Veterinária, ao Laboratório de Biologia Molecular do Departamento de Imunologia e Bioquímica do Instituto de Ciências Biológicas e à Pró-Reitoria de Pesquisa da Universidade Federal de Minas Gerais pelo suporte necessário para completar este estudo.

\section{Referência}

1. Grove JE, Bruscia E, Krause DS. Plasticity of bone marrow-derived stem cells. Stem Cells, v.22, p.487500, 2004;22(4):487-500. Disponível em : http://www.ncbi.nlm.nih.gov/pubmed/15277695

2. Dominici ML, Le Blanc K, Mueller I, Slaper-cortenbach I, Marini F, Krause D, et al. Minimal criteria for defining multipotencial mesenquimal stromal cells. The international society for cellular therapy position statement. Cytotherapy. 2006:8(4):315-7. Disponível em: http://www.ncbi.nlm.nih.gov/pubmed/?term=Minimal+criteria+for+defining+multipotencial+mesenquimal+ stromal+cells.+The+international+society+for+cellular+therapy+position+statement

3. Bobis S, Jarocha D, Majka M. Mesenchymal stem cells: characteristics and clinical applications. Folia Histochem Cytobiol. 2006;44(4):215-30. Disponível em : http://www.ncbi.nlm.nih.gov/pubmed/?term=Mesenchymal+stem+cells\%3A+characteristics+and+clinical+a pplications.+Folia+Histochemica+Cytobiologica

4. Presnell SC, Petersen B, Heidaran M. Stem cells in adult tissues. Semin Cell Dev Biol. 2002;13(5):369-76. Disponível em: http://www.ncbi.nlm.nih.gov/pubmed/12324219

5. Neupane M, Chang CC, Kiupel M, Yuzbasiyan-Gurkan V. Isolation and characterization of canine adipose-derived mesenquimal stem cells. Tissue Eng Part A. 2008;14(6):1007-15. Disponível em: http://www.ncbi.nlm.nih.gov/pubmed/19230125

6. Alves EG, Serakides R, Boeloni JN, Rosado IR, Ocarino NM, Oliveira HP, et al. Comparison of the osteogenic potential of mesenchymal stem cells from the bone marrow and adipose tissue of Young dogs. BMC Vet Res. 2014;2:10(1):190. Disponível em: http://www.ncbi.nlm.nih.gov/pubmed/25178540 
7. Tae S, Lee S, Park J, Im GI. Mesenchymal stem cells for tissue engineering and regenerative medicine. Biomed Mater. 2006;1(2):63-71. Disponível em: http://www.ncbi.nlm.nih.gov/pubmed/18460758

8. Yoshimura H, Muneta T, Nimura A, Yokoyama A, Koga H, Sekiya I. Comparison of rat mesenchymal stem cells derived from bone marrow, synovium, periosteum, adipose tissue and muscle. Cell Tissue Res. 2007;327(3):449-62. Disponível em: http://www.ncbi.nlm.nih.gov/pubmed/17053900

9. Filioli Uranio M, Valentini L, Lange-Consiglio A, Caira M, Guaricci AC, L’Abbate A, et al. Isolation, proliferation, cytogenetic and molecular characterization and in vitro differentiation potency of canine stem cells from foetal adnexa: a comparative study of amniotic fluid, amnion and umbilical cord matrix. Mol Reprod Dev. 2011;78(5):361-73. Disponível em: http://www.ncbi.nlm.nih.gov/pubmed/?term=Isolation\%2C+proliferation\%2C+cytogenetic+and+molecular+ characterization + and + in + vitro+differentiation+potency + of + canine + stem + cells + from + foetal + adnexa $\% 3 A+a$ +comparative+study+of+amniotic+fluid\%2C+amnion+and+umbilical+cord+matrix

10. Spencer ND, Chun R, Vidal MA, Gimble JM, Lopes MJ. In vitro expansion and differentiation of fresh and revitalized adult canine bone marrow-derived and adipose tissue-derived stromal cells. Vet J. 2012;191(2):231-9. Disponível em: http://www.sciencedirect.com/science/article/pii/S1090023311000050

11. Zuk PA, ZHU M, MIZUNO H, Huang J, Futrell JW, Katz AJ, et al. Multilineage cells from human adipose tissue: implications for cell-based therapies. Tissue Eng. 2001;7(2):211-28. Disponível em: http://www.ncbi.nlm.nih.gov/pubmed/?term=Multilineage+cells+from+human+adipose+tissue\%3A+implica tions+for+cell-based+therapies.+Tissue+Engineering

12. Lee WS, Suzuki Y, Graves SS, et al. Canine bone marrow-derived mesenchymal stromal cells suppress alloreactive lymphocyte proliferation in vitro but fail to enhance engraftment in canine bone marrow transplantation. Biol Blood Marrow Transplant. 2011;17(4):465-75. Disponível em: http://www.ncbi.nlm.nih.gov/pubmed/?term=Canine+bone+marrow-

derived+mesenchymal+stromal+cells+suppress+alloreactive+lymphocyte+proliferation $+\mathrm{in}+\mathrm{vitro}+\mathrm{but}+$ fail $+\mathrm{t}$ o+enhance+engraftment+in+canine+bone+marrow+transplantation. + Biology + of + Blood + and + Marrow + Tran splantation $\% 2 \mathrm{C}$

13. Csaki C, Matis U, Mobasheri A, Shakibaei M. Co-culture of canine mesenchymal stem cells with primary bone-derived osteoblasts promotes osteogenic differentiation. Histochem Cell Biol. 2009;131(2):251-66. Disponível em: http://www.ncbi.nlm.nih.gov/pubmed/?term=Coculture+of+canine+mesenchymal+stem+cells+with+primary+bone-

derived+osteoblasts+promotes+osteogenic+differentiation

14. Chung D, Hayashi K, Toupadakis CA, Wong A, Yellowley CE. Osteogenic proliferation and differentiation of canine bone marrow and adipose tissue derived mesenchymal stromal cells and the influence of hypoxia. Res Vet Sci. 2012;92(1):66-75. Disponível em: http://www.ncbi.nlm.nih.gov/pubmed/?term=Osteogenic+proliferation+and+differentiation+of+canine+bone + marrow+and+adipose+tissue+derived+mesenchymal+stromal+cells+and+the+influence+of+hypoxia.+Rese arch+in+Veterinary+Science\%2C

15. Piermattei DL, Flo GL, De Camp CE. Handbook of small animal orthopedics and fracture repair. $4^{\text {th }}$ ed. St. Louis:Saunders; 2006. 832p. Disponível em: http://www.sciencedirect.com/science/book/9780721692142

16. De Ugarte DA, Morizono K, Elbarbary A, Alfonso Z, Zuk PA, Zhu M, et al. Comparison of Multilineage cells from human adipose tissue and bone marrow. Cells Tissues Organs, 2003;174(3):101-9. Disponível em: http://www.ncbi.nlm.nih.gov/pubmed/12835573

17. Eslaminejad WB, Taghiyar L. Study of the structure of canine mesenchymal stem cell osteogenic culture. Anat Histol Embryol. 2010; 39(5):446-55. Disponível em: 
http://www.ncbi.nlm.nih.gov/pubmed/?term=Study+of+the+structure+os+canine+mesenchymal+stem+cell+ osteogenic+culture.+Anatomia\%2C+Histologia\%2C+Embryologia\%2C

18. Seo M, Jeong YH, Park JR, Park SB, Rho KH, Kim HK, et al. Isolation and characterization of canine umbilical cord blood-derived mesenchymal stem cells. J Vet Sci. 2009;10(3):181-7. Disponível em: http://www.ncbi.nlm.nih.gov/pubmed/?term=solation+and+characterization+of+canine+umbilical+cord+blo od-derived+mesenchymal+stem+cells.+Journal+of+Veterinary+Science

19. Rozemuller H, Prins HJ, Naaijkens B, Staal J, Buhring HJ, Martens AC. Prospective isolation of mesenquimal stem cells from multiples mammalian species using cross-reaction anti human monoclonal antibodies. Stem Cells Dev. 2010;19(12):1911-21. Disponível em: http://online.liebertpub.com/doi/abs/10.1089/scd.2009.0510

20. Vieira NM, Brandalise V, Zucconi E, Secco M, Strauss BR, Zatz M. Isolation, characterization, and differentiation potential of canine adipose-derived stem cells. Cell Transplant. 2010;19(3):279-89. Disponível em:http://www.ncbi.nlm.nih.gov/pubmed/?term=Isolation\%2C+characterization\%2C+and+differentiation+p otential+of+canine+adipose-derived+stem+cells.+Cell+Transplantation

21. Martinello T, Bronzini I, Maccatrozzo L, Mollo A, Sampaolesi M, Mascarello F, et al. Canine adiposederived-mesenchymal stem cells do not lose stem features after a long-term cryopreservation. Res Vet Sci. 2011;91(1):18-24. Disponível em: http://www.ncbi.nlm.nih.gov/pubmed/20732703

22. Schwarz C, Leicht U, Rothe C, Drosse I, Luibl V, Rocken M, et al. Effects of different media on proliferation and differentiation capacity of canine, equine and porcine adipose derived stem cells. Res Vet Sci. 2012;93(1):457-62. Disponível em: http://www.sciencedirect.com/science/article/pii/S0034528811003493

23. Levi B, Nelson ER, Brown K, James AW, Xu D, Dunlevie R, et al. Differences in osteogenic differentiation of adipose-derived stromal cells from murine, canine, and human sources in vitro and in vivo.

Plast Reconstr Surg.2011;128(2):373-86. Disponível http://www.ncbi.nlm.nih.gov/pubmed/?term=Differences+in+osteogenic+differentiation+of+adiposederived+stromal+cells+from+murine $\% 2 \mathrm{C}+$ canine $\% 2 \mathrm{C}+$ and+human+sources+in+vitro+and+in+vivo. 